\title{
Talgoxens Parus major antal och häckningsbiologi - resultat av 25 års holkstudier
}

\author{
Numbers and breeding biology of the Great Tit Parus major - results of a 25 \\ year nest-box study
}

JAN-ERIC NILSSON

\begin{abstract}
A nest-box population of Great Tits Parus major was followed in 1986-2010. Maximum number of breeding attempts was three times higher than the minimum number but there was no significant trend through 2005. The number of nest-boxes declined from 94 to 55 during the last five years making it difficult to interpret the recent trend but most likely there was an increase. $17 \%$ of the first breeding attempts failed and resulted in replacement clutches. The number of second clutches was $13 \%$ of the number of first clutches. There was no correlation between population size and winter temperature. There was no significant advancement of laying date in

spite of the fact laying date was correlated with April temperature and that local April temperature showed a significant positive trend during the study period. Mean clutch size was 9.2 eggs. The number of fledglings was 4.65 , which is low compared to other studies. Replacement and second clutches produced 4.37 fledglings. Both clutch size and number of fledglings declined during the study period.

Jan-Eric Nilsson, Sänninge Brohagen 1, 57397 Tranås. E-mail:j-e.n@telia.com
\end{abstract}

Received 1 March 2011, Accepted 6 September 2011, Editor: S. Svensson

\section{Inledning}

Den första delen av min studie av det holkhäckande fågelbeståndet i Linderås (Tranås kommun, Jönköpings län) har tidigare redovisats (Nilsson 2008). Den omfattade, förutom en allmän presentation av undersökningsområdet också en biotopbeskrivning, den metodik som använts, samt en redovisning av samtliga häckningar under de 20 åren 1986-2005. Huvudinnehållet bestod dock av en redovisning och analys av de häckningsbiologiska data som insamlats för den svartvita flugsnapparen Ficedula hypoleuca.

Denna rapport omfattar motsvarande uppgifter för talgoxen Parus major och när det gäller de grundläggande uppgifterna om undersökningsområdet och metoderna hänvisar jag till den första uppsatsen. Studien avslutades i sin fulla omfattning 2005, men jag har fortsatt att följa häckningarna i ett reducerat antal holkar. Jag har därför valt att här även ta med vissa data från de följande åren, 2006-2010. Detta gäller uppgifter om äggläggningsdatum, kullstorlek och häckningsutfall eftersom jag anser att dessa inte påverkats nämnvärt av reduktionen av antalet holkar.
Mycket har skrivits om talgoxens häckningsbiologi, men jag har i denna uppsats i huvudsak begränsat mig till jämförelser med två liknande studier, den ena i Värmland (Råda) under nästan samma tidsperiod, 1985-2004 (Borgström 2007), den andra i Örebrotrakten under åren 1948-2008 (Schölin 2009). I den fortsatta framställningen hänvisar jag till dessa som Råda- resp. Örebrostudierna.

Talgoxens häckningsbiologi är klart besvärligare att få grepp om än den svartvita flugsnapparens. Den sistnämnde har inga andrakullar och omläggningar är extremt ovanliga. Talgoxen är däremot mycket störningskänslig och omläggningar sker ofta. Antalet andrakullar är relativt få, men kan vissa år vara mer frekventa. Gränsdragningen mellan omläggningar och andrakullar är ibland svår. Här delar jag Borgströms uppfattning, d.v.s. att ringmärkningen måste vara det enda helt säkra kriteriet. Liksom i Råda-studien har min strävan därför varit att ringmärka så många honor som möjligt för att på detta sätt fastställa huruvida det är fråga om en omläggning eller en andra kull. Under perioderna 1996-1999 och 2006-2010 har dock ingen ringmärkning av honor skett, varför fördelningen 
mellan omläggningar och andrakullar grundar sig på en mer subjektiv bedömning. Ambitionen att ringmärka honorna krockar stundom med strävan att inte störa dem under senare delen av äggläggningen eller under den första ruvningsveckan, då de erfarenhetsmässigt är extremt störningskänslig.

Den följande redovisningen omfattar således $\mathrm{i}$ huvudsak åren 1986-2005, där beståndsutvecklingen avser de 94 holkar som satt på samma plats under de 20 åren. Uppgifter insamlade i ytterligare 39 holkar som fanns åren 1986-2000, och som ingick i Nilsson (2008), har inte använts i föreliggande uppsats. Sedan det egentliga projektet avslutades 2005 har holkantalet reducerats ytterligare och ambitionsnivån sänkts något. Antalet holkar sjönk stegvis till 55 stycken år 2010. Vid en jämförelse av resultat och slutsatser från de andra studier jag refererar till finns stora överensstämmelser, men också en del avvikelser. Dessa kommer att diskuteras i den fortsatta framställningen.

\section{Resultat och diskussion}

\section{Det holkhäckande beståndet}

En jämförelse med Råda-studien visar en mindre avvikelse när det gäller artsammansättningen hos det holkhäckande beståndet i de två områdena. Borgström anger andelarna till 50\% för den svartvita flugsnapparen, $35-40 \%$ för talgoxen och $10-15 \%$ för övriga arter. Mina siffror visar en högre andel flugsnappare (57\%), en lägre andel talgoxar $(31 \%)$ och ungefär samma andel övriga arter $(12 \%)$. Att siffrorna varierar något har säkert sin förklaring i att holkarna varit uppsatta i olika biotoper med varierande konkurrens från andra arter, födotillgång eller andra orsaker som inte går att säkert fastställa.

\section{Beståndsutveckling}

Som framgår av Figur 1 varierar antalet häckande talgoxar i de 94 holkarna ganska kraftigt under undersökningsperioden, ett faktum som är likartat även i övriga studier. Mina siffror visar en variation mellan bottenåren 1987 och 1995 med 12 påbörjade häckningar och toppåret 2003 med 35 stycken, d.v.s. en tredubbling. Motsvarande siffror från Värmland varierar mellan 23 par (1985) och 72 par (1992) och i Örebro mellan 13 par (1975) och 41 par (2007), även här en ungefärlig tredubbling mellan minimum och maximum. En jämförelse av beståndsutvecklingen i mitt område under enskilda år med de övriga studierna visar ingen samstämmighet, tvärtom ser det ibland ut som goda år i Småland motsvaras av ganska dåliga i Råda/Örebro och vice versa.

En fråga som jag närmare ville studera var, huruvida vinterns stränghet påverkade antalet häckande par den kommande säsongen. Avvikelser från medeltemperaturen vid Jönköpings flygplats (SMHI, månaderna december-februari) jämfördes med det häckande beståndet, men inte heller här kunde någon samvariation konstateras. Samma slutsats drogs i Örebrostudien, där motsvarande jämförelse gjordes. Mycket tyder därför på, att talgoxens häckningsfrekvens är lokalt betingad och främst beror på att arten är ganska stationär och därför påverkas av varierande lokalklimat, födotillgång m.m.

I medeltal påbörjade talgoxen 23 förstakullar per år och någon tydlig tendens till ökning eller minskning kan inte ses. Endast sex procent av variationen kan förklaras av regressionen för antal par mot årtalet $\left(\mathrm{R}^{2}=0,06\right)$. Noterbart är möjligen, att efter flera goda år (1989-1991), beståndet tydligen nått

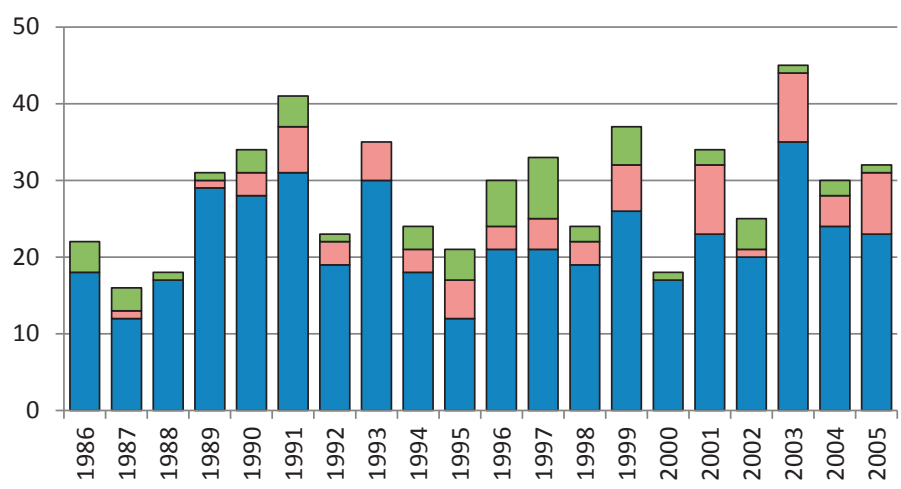

$\square$ 1:a kullar $\square$ Omläggningar Replacements $\square 2$ :a kullar
Figur 1. Antal kullar av olika kategorier åren 1986-2010 med 94 holkar varje år. Number of clutches of different categories (1st, replacement and 2nd clutches) in 1986-2010 with 94 nestboxes every year. 
Figur 2. Procent holkar besatta av talgoxe (blå) och svartvit flugsnappare (grön). 1986-2010 fanns 94 holkar, därefter stegvis sjunkande till 55 år 2010.

Percent nest-boxes used by Great Tit (blue) and Pied Flycatcher (green). 94 nest-boxes in 1986-2010, then stepwise reduced to 55 in 2010.

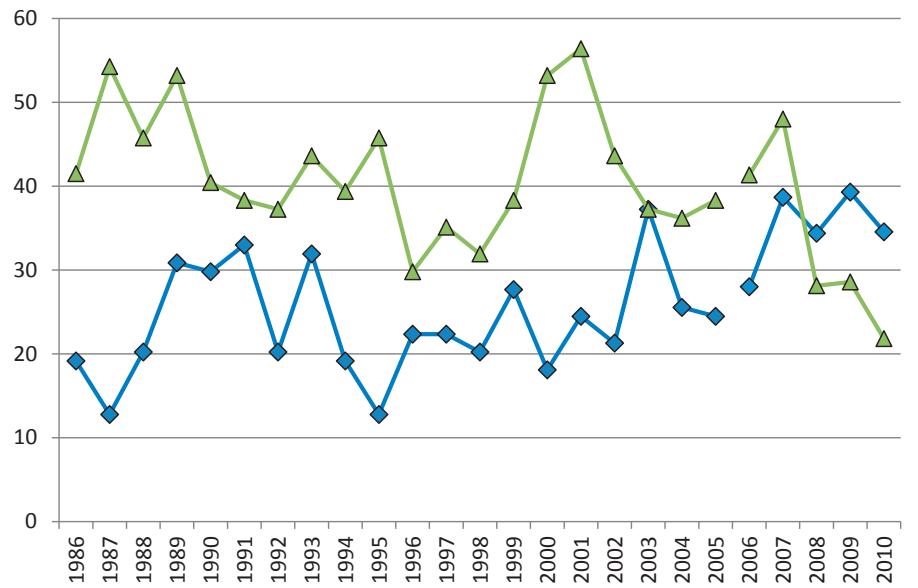

någon form av maximum. Både hösten 1990 och 1991 fick jag nämligen rapporter om att av mig pull-märkta talgoxar kontrollerats på utsträck från Falsterbo fågelstation.

I Örebrostudien visar Schölin att talgoxen ökat relativt kraftigt under senare år. Eftersom antalet holkar varierat visar han detta genom att fastställa andelen förstakullar av talgoxe i procent av det totala antalet tillgängliga holkar. En motsvarande omräkning av mitt material framgår av Figur 2. Här framgår att beståndet av talgoxar var tämligen stabilt fram till 2000-talets början, då en ökning tydligt kan ses, precis som i Örebrotrakten. Ökningen är signifikant och trenden förklarar 27\% av variationen. Tolkningen kompliceras dock av att antalet holkar stegvis reducerats mellan 2005 och 2010. Även antalet blåmesar Cyanistes caeruleus har ökat, men detta material är ännu inte bearbetat. Jag har valt att även redovisa utvecklingen hos den svartvita flugsnapparen i samma figur och kan konstatera, att denna art minskat under senare år efter att ha haft en ganska stabil förekomst under de första 20 åren. Vad orsaken kan vara till dessa fluktuationer eller trender är svårt att avgöra. Att talgoxens ökning skulle ske på den svartvita flugsnapparens bekostnad, d.v.s. att den senare skulle bli utträngd p.g.a. ökad konkurrens anser jag inte vara troligt, då det varje år funnits ett stort antal holkar som inte varit ockuperade (ca $35 \%$, variation 16-48\%). En möjlig orsak till talgoxens och blåmesens ökning kan däremot vara den markanta minskningen av övriga mesar (entita Poecile palustris, talltita Poecile montana och svartmes Periparus ater) i området, innebärande att de förstnämnda kan ha fătt ökat livsutrymme. Den svartvita flug- snapparen hade 2010 ett bottenår med endast 12 häckningar. Här är jag ganska säker på orsaken brist på honor. Hanarna kom i normalt antal och besatte snabbt lämpliga holkar. I flera fall sjöng de oavbrutet i två till tre veckor, dock utan att en partner dök upp. Något hade tydligen hänt under honornas flyttning som gjorde att de aldrig kom fram till målet.

I Figur 1 redovisas också antalet omläggningar (74 st) och andrakullar (56 st) fördelade på de 20 häckningssäsongerna, vilka kommenteras längre fram i rapporten.

\section{Äggläggningsstart}

I Figur 3 redovisas det årliga medelvärdet för värpstarten för talgoxens förstakullar under samtliga 25 år och omfattar 611 registrerade kullar. För hela pe-

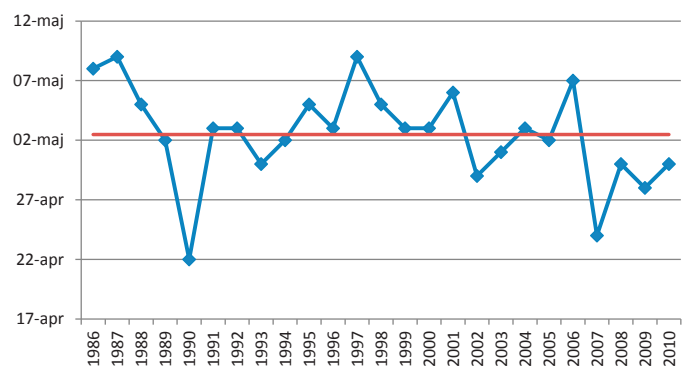

Figur 3. Årligt medeldatum för läggningsstart hos förstakullar. Röd linje är medeldatum för hela perioden.

Annual mean date of onset of laying of first clutches. Red line is mean date for the whole period. 
Medeltemperatur Mean temperature April

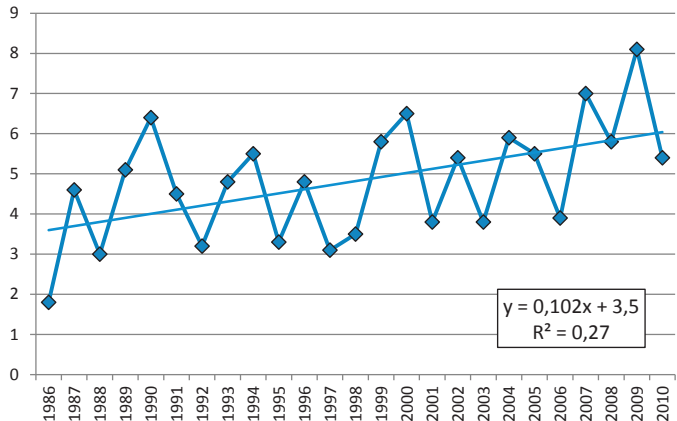

Värpstart Clutch initiation

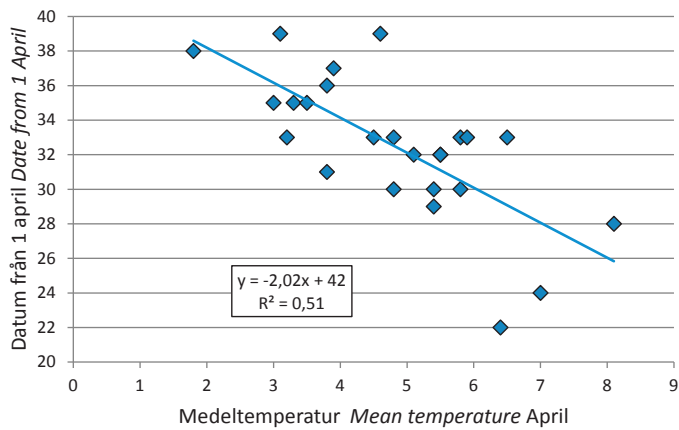

Figur 4. Medeltemperaturen för april i Norrköping (övre diagrammet) och värpstarten $\mathrm{i}$ förhållande till temperaturen (nedre diagrammet).

Mean April temperature at Norrköping (upper diagram) and clutch initiation in relation to temperature (lower diagram).

rioden blev medeldatum den 2 maj, med tidigaste medeldatum för läggstarten den 22 april (1990) och senaste den 9 maj (1987 och 1997). Även 2007 var ett år med tidig värpstart (medeldatum 24 april) vilket sammanfaller med Örebrostudien. Det tidigaste ägget någonsin hittades redan den 8 april under det extrema året 1990, hela två veckor före det årets medeldatum.

Som synes varierade tidpunkten för värpstart ganska kraftigt mellan de olika åren men ingen tydlig tendens till tidigare datum kan påvisas (trend $=-0,18 ; \mathrm{R}^{2}=0,11$; ej signifikant). Inte heller Råda-studien visade någon tendens till tidigare datum, medan Örebrostudien visade en nästan signifikant sådan tendens. En jämförelse med studien i Råda visar att äggläggningen där i genomsnitt påbörjades en vecka senare (10 maj) och i Örebro den 6 maj, d.v.s. några dagar senare än i norra Småland. Det rådde en god samstämmighet mellan läggdatum i de tre studierna $(p<0,001$ i alla tre jämförel- serna), något som inte är överraskande eftersom temperaturen varierar likartat mellan åren på alla lokalerna.

Både Borgström och Schölin visade på ett klart samband mellan medeltemperaturen $i$ april och värpstarten. Även i min studie var sambandet mellan apriltemperaturen och värpstarten höggradigt signifikant. Värpstarten inföll i genomsnitt två dagar tidigare per grad högre temperatur $(b=-2,02$; $\mathrm{p}<0,0001$; Figur 4). Så mycket som hälften av variationen i värpdatum kunde förklaras av apriltemperaturen $\left(\mathrm{R}^{2}=0,51\right)$. Apriltemperaturen i Jönköping ökade med i genomsnitt 0,1 grad per år (SMHI; $\left.\mathrm{R}^{2}=0,26 ; \mathrm{p}<0,01\right)$. Trots detta och trots det starka sambandet mellan apriltemperaturen och värpstarten uppvisade talgoxarna i Tranås inte någon signifikant reaktion på denna trend (Figur 3).

Att häckningarna påbörjas ca en vecka senare i Råda och i Örebro är väl inte så förvånande, då områdena ligger nordligare än mitt. Förbryllande är dock en jämförelse med det skånska materialet från åren 1969-1978 i Linnebjer (Källander 1983), där medeldatum för talgoxarnas första ägg var den 9 maj, d.v.s. ungefär samma som i Värmland. Om nord-sydteorin skulle gälla borde de skånska häckningarna $\mathrm{i}$ huvudsak starta $\mathrm{i}$ april, men så skedde bara i 4,3 \% av fallen. En möjlig förklaring skulle kunna vara de olika klimattyper som råder i regionerna. Både Värmland, Örebro och norra Småland har vad vi kallar ett ganska utpräglat inlandsklimat, medan Skåne får anses ha ett mer typiskt kustklimat med något svalare vårar. Emellertid är en alternativ förklaring att läggstarten var avvikande sen just åren 1969-1978. Eftersom senare uppgifter från Linnebjer inte varit tillgängliga, har Hans Källander i brev meddelat att han på två andra lokaler (Revinge och Vombs fure) funnit att äggläggningen i genomsnitt började 8-10 dagar senare 1971-1974 jämfört med 1988-1996. Under den senare perioden var medeldatum i Revinge och Vombs fure 29 april. Samma år var medeldatum i mitt område 2 maj, alltså tre dagar senare. Det verkar därför som om nord-sydteorin trots allt håller även om skillnaden mellan Linderås och Skåne inte är särskilt stor.

Som tidigare framgått (Figur 1) har 74 säkra omläggningar skett av spolierade eller övergivna förstakullar. Dessa har oftast skett i närliggande holkar som inte varit upptagna och relativt snabbt efter att den första kullen övergivits. Detta kunde ske under hela häckningscykeln, från slutet av äggläggningen till att ungarna kläckts. I det senare fallet var det oftast kyla och födobrist som var orsaken medan det i de tidigt övergivna kullarna nästan alltid var fråga om störningar av olika slag, t.ex. konkurrens. Da- 
tum för dessa omläggningar beror givetvis på när kullen överges och kan därför variera starkt från mitten av maj till första veckan i juni. Borgström bedömer att ca $25 \%$ av förstahäckningarna misslyckas och att en omläggning sker. I mitt material blev andelen ca $17 \%$.

Som andrakullar har jag liksom i övriga studier räknat kullar där talgoxeparet fătt ut minst en unge i förstakullen. Det har diskuterats huruvida andrakullar är vanliga eller sällsynta. I mitt material anser jag att det sistnämnda gäller, endast 56 säkra andrakullar kunde registreras $(12,6 \%$ av förstakullar). Värpstart i dessa kullar varierade med tidpunkten för den första kullens avslutande, men skedde i allmänhet i mitten av juni (10-25 juni, i medeltal 15 juni). Värpstarten i den senaste kullen $i$ mitt material skedde den 1 juli och innebar att ungarna flög ut $\mathrm{i}$ början av augusti.

\section{Kullstorlek}

Även denna redovisning avser samtliga holkar som undersökts under åren 1986-2010 och omfattar 628 förstahäckningar. Som framgår av Figur 5 varierar medelkullstorleken från 7,95 ägg/kull (2009) till 10,11 (1996) med ett medeltal på 9,20 ägg per kull. Medelkullstorleken visar en negativ trend under perioden med särskilt låga värden ett par av de senaste åren. Den genomsnittliga trenden är en sänkning med 0,04 ägg per år $\left(R^{2}=0,29 ; p<0,01\right)$. Samma trend noterades dock i Örebro och Råda. För de gemensamma årens medelkullstorlekar var korrelationskoefficienten $\mathrm{r}=0,68$ för Tranås-Råda, $\mathrm{r}=0,70$ för Tranås-Örebro och $\mathrm{r}=0,60$ för RådaÖrebro, samtliga signifikanta $(\mathrm{p}<0,01)$.

Orsaken till dessa variationer är svår att förklara, vilket också andra studier visar. Eftersom kullstor-

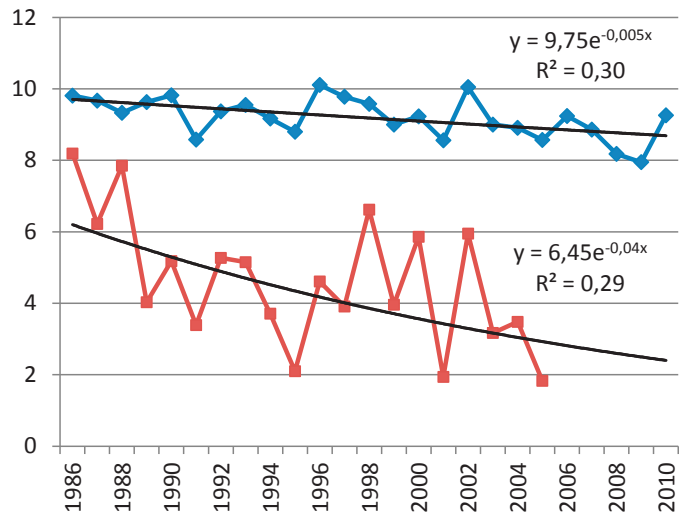

Figur 5. Årliga medelvärden för äggkullstorleken (övre) och antal flygga ungar (nedre). Antal ungar 2006-2010 visas inte enär holkarna hade modifierats för att minska predationen och värdena därför inte är jämförbara med tidigare.

Annual mean values for clutch size (upper) and number of fledglings (lower). Number of fledglings was not determined in 2006-2010.

leken styrs av ett flertal faktorer som har behandlats av många talgoxforskare avstår jag från en närmare analys i denna uppsats.

I Tabell 1 jämför jag mina data med fyra andra undersökningar såväl avseende medelkullstorleken som fördelningen av antalet ägg i kullarna. Medelkullstorleken ökar från söder mot norr. Den är således ca två ägg större i Skåne än i Uppland. En skillnad är de olika andelarna av små respektive stora kullar. Nästan $10 \%$ av kullarna i norr har 6 ägg eller färre, medan antalet stora kullar är mycket fåtaliga. I Skåne och Småland dominerar 10-kullar, i Råda och Örebro 9-kullar och i Uppland 8-kullar.

Det är intressant att notera att Källander och

Tabell 1. Kullstorlekens medelvärde och fördelning i procent på olika kullstorlekar i denna och andra studier. Mean clutch size and percentage of different clutch sizes in this and other studies.

\begin{tabular}{lrrrrrrrrr}
\hline Landskap & Medel & \multicolumn{7}{c}{ Kullstorlek Clutch size } \\
\cline { 2 - 10 } Province & Mean & $<7$ & 7 & 8 & 9 & 10 & 11 & 12 & $>12$ \\
\hline Skåne $^{1}$ & 9,85 & 3 & 5 & 13 & 20 & $\mathbf{2 6}$ & 21 & 8 & 5 \\
Småland $^{2}$ & 9,20 & 5 & 7 & 14 & 24 & $\mathbf{3 0}$ & 14 & 4 & 2 \\
Närke $^{3}$ & 8,72 & 4 & 10 & 27 & $\mathbf{3 3}$ & 20 & 4 & 1 & 0 \\
Värmland $^{4}$ & 8,74 & 6 & 12 & 25 & $\mathbf{2 8}$ & 21 & 7 & 2 & 0 \\
Uppland $^{5}$ & 7,83 & 10 & 22 & $\mathbf{4 8}$ & 16 & 3 & 1 & 1 & 0 \\
\hline
\end{tabular}

5544' N, 13¹8' E; 387 kullar clutches; 1970-1978; Källander (1983)

$257^{\circ} 58^{\prime} \mathrm{N}, 14^{\circ} 15^{\prime} \mathrm{E}$; 628 kullar clutches; 1986-2010: denna studie this study

3 59॰14' N, 15¹3' E; 1115 kullar clutches; 1948-2008; Schölin (2009)

${ }^{4} 60^{\circ} 00^{\prime} \mathrm{N}, 13^{\circ} 36^{\prime} \mathrm{E}$; 950 kullar clutches; 1985-2004; Borgström (2007)

${ }^{5} 60^{\circ} 19^{\prime} \mathrm{N}, 16^{\circ} 56^{\prime} \mathrm{E}$; 209 kullar clutches; 1952-1963; Johansson (1972) 
Tabell 2. Kullstorlekens medelvärde för förstakullar med värpstart under olika tidsperioder i Tranås (denna studie) och i Råda, Värmland.

Mean size of first clutches with onset of laying in different periods at Tranås (this study) and Råda, Värmland.

\begin{tabular}{rrrrr}
\hline \multicolumn{2}{c}{ Tranås, Småland } & & \multicolumn{2}{c}{ Råda, Värmland } \\
\cline { 1 - 2 } \cline { 5 - 5 } Period & $\begin{array}{c}\text { Medel } \\
\text { Mean }\end{array}$ & & $\begin{array}{c}\text { Medel } \\
\text { Mean }\end{array}$ & Period \\
& 9,67 & & - & - \\
\hline$-15 / 4$ & 10,00 & & - & - \\
$21-20 / 4$ & 9,98 & & - & - \\
$26-30 / 4$ & 9,55 & & 9,36 & $24-28 / 4$ \\
$1-5 / 5$ & 9,36 & & 8,87 & $29 / 4-3 / 5$ \\
$6-10 / 5$ & 9,14 & & 8,87 & $4-8 / 5$ \\
$11-15 / 5$ & 8,68 & & 8,74 & $9-13 / 5$ \\
$16-20 / 5$ & 8,17 & & 8,77 & $14-18 / 5$ \\
$21-25 / 5$ & 8,33 & & 8,39 & $19-23 / 5$ \\
$26-30 / 5$ & - & & 8,08 & $24-28 / 5$ \\
\hline
\end{tabular}

Borgström kommit till olika uppfattningar om talgoxens tendens att lägga större eller mindre kullar beroende på värpstarten. Källander visar att de tidigare kullarna är minst och sedan ökar, medan Borgström i sitt siffermaterial konstaterar att det är tvärtom $(9,36$ ägg/kull i april och 8,08 i slutet av maj). Tyvärr har jag använt andra tidsintervaller än Borgström, men menar att resultatet sammanfaller med den trend han anger, d.v.s. äggantalet sjunker vid senare kullar. Mitt material presenteras i Tabell 2 och jämförs med resultaten i Råda (notera viss divergens i tidsintervallerna).

De 74 omläggningar som under åren 1986-2005 registrerades hade en medelkullstorlek på 7,73 ägg/ kull, d.v.s. ca 1,5 ägg färre än i förstakullarna. I Råda-studien var medelkullstorleken för omläggningarna 7,74 ägg, exakt ett ägg mindre än i förstakullarna.

Antalet registrerade andrakullar är i denna studie 56 (12,6\% av förstakullarna) och medelkullstorleken blev här 7,09 ägg, d.v.s. 2,1 ägg färre än i förstakullarna. En intressant iakttagelse kan göras vid jämförelse av uppgifterna i Tabell 1 med angivna kullstorlekar hos andrakullar i de övriga studierna. I Skåne, som hade störst förstakullar, var den andra kullen 2,6 ägg mindre (7,26 ägg/kull), i min studie 2,1 ägg mindre (7,09 ägg/kull), i Värmland 1,4 ägg mindre (7,32 ägg/kull) och i Uppland 0,6 ägg mindre (7,18 ägg/kull). Trots att förstakullarna således varierade med ca 2 ägg från den sydligaste till den nordligaste studien visar det sig att andrakullarna varierade betydligt mindre (7,09-7,32 ägg/kull, d.v.s. 0,23 ägg). Vad orsaken är till detta fenomen är inte känt.

\section{Häckningsutfall}

När det gäller häckningsutfallet (flygga ungar) hos den svartvita flugsnapparen visade det sig, att det låg ca $25 \%$ lägre än i de andra studier jag jämförde med. Jag kan nu notera att i stort samma förhållande gäller för talgoxen. I Tabell 3 och Figur 5 redovisas utvecklingen under perioden 1986-2005 och materialet bygger på 515 häckningar. Att jag inte medtagit åren 2006-2010 beror på, att jag efter projektets slut modifierade holkarna med djupare ingångshål, som reducerade bl.a. mårdens möjligheter till predation. Därmed skulle inte materialet vara fullständigt jämförbart. I medeltal för hela tjugoårsperioden blev antalet flygga ungar endast 4,65 per kull, klart mycket sämre jämfört med 6,81 flygga per kull i Råda och 5,76 per kull i Örebro. Det är svårt att hitta orsaken till skillnaderna både när det gäller talgoxens och den svartvita flugsnapparens dåliga resultat just i mitt område. Skillnaden i äggkullstorlek (Tabell 1) är inte tillräcklig. Kanske är våra studier genomförda i skilda naturmiljöer, med olika väderfaktorer och födotillgång, men jag tror att det är predationstrycket som är mest avgörande. Mården har under vissa år orsakat stora förluster i mitt område och så även de kalla perioder som ofta förekommer på det småländska höglandet och ibland sammanfaller med talgoxens matningsperiod. Jag kan givetvis inte heller utesluta att min ambition att ringmärka så många honor som möjligt, trots tidigare nämnda försiktighetsåtgärder, bidragit till att några kullar övergetts.

Schölin visar att häckningsframgången minskat markant under senare år (från 8,01 ungar/kull under åren 1948-1957 till 6,19 åren 1998-2008). Detta gäller även för denna studie, där medeltalet under den första 5-årsperioden (1986-1990) var 6,29 flygga ungar per kull och under de sista fem åren (2001-2005) endast 3,27 ungar/kull. Som synes av tabellen kan vissa år betecknas som riktiga "katastrofår" (1995, 2001 och 2005), medan andra varit mer framgångsrika. Noterbart är också att undersökningens första år (1986) var det bästa med 8,19 ungar per kull och att det sista året (2005) var det sämsta med 1,83 flygga ungar per kull.

Talgoxens omläggningar och andrakullar lyckades relativt sett något bättre om hänsyn tas till att kullarna redan från början var mindre. Utfallet blev för omläggningarna 4,04 flygga ungar/kull och för andrakullarna 4,37 ungar/kull. 
Tabell 3. Häckningsresultat för talgoxe 1986-2005.

Breeding performance of the Great Tit in 1986-2005.

\begin{tabular}{lrrrrrrrr}
\hline År & Kullar & Ägg & Kläckta & $\begin{array}{r}\text { \% kläckta } \\
\text { av lagda }\end{array}$ & Flygga & $\begin{array}{r}\text { \% flygga } \\
\text { av kläckta } \\
\text { \% fledged } \\
\text { of hatched } \\
\text { oflaid }\end{array}$ & $\begin{array}{r}\text { Flygga/ } \\
\text { kledgll }\end{array}$ & $\begin{array}{r}\text { \% flygga av } \\
\text { Flagda ägg } \\
\text { \% fledged of } \\
\text { laid eggs }\end{array}$ \\
\hline 1986 & 21 & 206 & 172 & 83 & 172 & 100 & 8,19 & 83 \\
1987 & 18 & 174 & 151 & 87 & 112 & 74 & 6,22 & 64 \\
1988 & 27 & 252 & 217 & 86 & 212 & 98 & 7,85 & 84 \\
1989 & 35 & 337 & 199 & 59 & 141 & 71 & 4,03 & 42 \\
1990 & 45 & 442 & 340 & 77 & 233 & 69 & 5,18 & 53 \\
1991 & 38 & 326 & 217 & 67 & 129 & 59 & 3,39 & 40 \\
1992 & 30 & 281 & 199 & 71 & 158 & 79 & 5,27 & 56 \\
1993 & 33 & 315 & 236 & 75 & 170 & 72 & 5,15 & 54 \\
1994 & 24 & 220 & 145 & 66 & 89 & 61 & 3,71 & 41 \\
1995 & 10 & 88 & 52 & 59 & 21 & 40 & 2,10 & 24 \\
1996 & 18 & 182 & 106 & 58 & 83 & 78 & 4,61 & 46 \\
1997 & 23 & 225 & 163 & 72 & 90 & 55 & 3,91 & 40 \\
1998 & 24 & 230 & 182 & 79 & 159 & 87 & 6,62 & 69 \\
1999 & 28 & 252 & 161 & 64 & 111 & 69 & 3,96 & 44 \\
2000 & 22 & 203 & 158 & 78 & 129 & 82 & 5,86 & 64 \\
2001 & 18 & 154 & 75 & 49 & 35 & 47 & 1,94 & 23 \\
2002 & 20 & 201 & 124 & 62 & 119 & 96 & 5,95 & 59 \\
2003 & 35 & 315 & 185 & 59 & 111 & 60 & 3,17 & 35 \\
2004 & 23 & 205 & 121 & 59 & 80 & 66 & 3,48 & 39 \\
2005 & 23 & 197 & 97 & 49 & 42 & 43 & 1,83 & 21 \\
\hline Total & 515 & 4805 & 3300 & $\mathrm{M}=69 \%$ & 2396 & $\mathrm{M}=73 \%$ & $\mathrm{M}=4,65$ & $\mathrm{M}=50 \%$ \\
\hline & & & & & & & &
\end{tabular}

Av Tabell 4 framgår under vilka skeden i talgoxens häckningscykel förlusterna skett. Endast knappt $20 \%$ av kullarna lyckades helt, d.v.s. att alla ägg i kullarna kläcktes och resulterade i flygga ungar. Huvuddelen av förlusterna skedde under ruvningstiden och den vanligaste orsaken var att ett eller flera ägg inte kläcktes ( $43 \%$ av samtliga kullar). Oftast (72\%) handlade det om att ett eller två ägg förblev okläckta, men även större antal har noterats (5-9). I många fall tog den svartvita flugsnapparen snabbt över holkar som talgoxen av olika anledningar övergett (predation, ringmärkning, kyla etc.). Jag har hittat såväl döda talgoxar som flugsnappare (flest hanar) i holkarna. Konkurrensen mellan de två arterna har debatterats i flera andra studier och olika resultat och slutsatser har redovisats. Mitt underlag medger ingen säker slutsats om förekomst av direkta strider eftersom dessa försiggår i holken och inte lätt kan observeras.

När det gäller förluster under matningsskedet är bilden något annorlunda. I några enstaka fall har även här den svartvite flugsnapparen lyckats överta holken. De flesta orsakerna är dock noterade som predatorers framfart, främst mård (18 fall), okänt djur (28), större hackspett (3) men också dåligt väder (15). I övriga fall är orsaken okänd. Här är det därför rimligast att anta att flugsnapparen tagit holken i besittning efter en misslyckad talgoxhäckning. Även för kullar där några av ungarna klarat sig var mården, andra predatorer och kylan de dominerande orsakerna till förluster. I mina kontroller av holkarna har jag vid flera tillfällen kommit strax efter ett angrepp av mården och kunnat ta bort de borester som täckt ingångshålet. Föräldrarna har då fortsatt mata de ungar som hamnat på holkens botten och fått dem på vingarna. I Tabell 4 redovisas även de kullar, där en eller flera ungar lämnats att dö, medan övriga blivit flygga. Här torde matbrist (kyla) vara huvudorsaken.

En analys av häckningsutfallet och orsakerna till förluster i omläggningar och andrakullar visar i stora drag samma bild som vid förstahäckningarna.

\section{Ringmärkning och kontroller}

Ringmärkning av de holkhäckande fåglarna inom undersökningsområdet avslutades 2005, med uppehåll under åren 1996-1999 och omfattade 293 
honor och 2651 ungar. Talgoxen var i huvudsak en stannfågel, men vissa år genomfördes längre flyttningsrörelser. I mitt material finns tre sådana noterade, alla efter de goda reproduktionsåren i början av 1990-talet. Såväl 1990 som 1991 kontrollerades en av mig tidigare under året som unge ringmärkt talgoxe vid Falsterbo fågelstation, båda troligen på väg att lämna landet. År 1994 återfanns en annan som unge märkt fågel i Dala-Floda i Dalarna (ringmärkt i maj 1992). Materialet är litet, men indikerar att även talgoxens ungfåglar vissa år helt lämnar hemtrakterna och ger sig av långa sträckor. I övrigt har bara en som unge märkt fågel återfunnits utanför holkområdet, i Vireda (ca 2 mil söder om Linderås). Vid analys av motsvarande material för den svartvita flugsnapparen kunde konstateras, att årsungarna sällan återkom till hemtrakten, medan detta oftare förekom hos honor som tidigare häckat i området. Av Tabell 5 framgår att 34 kontroller gjordes av ringmärkta ungar av talgoxen och som väntat återfanns de flesta året efter märkningen, varefter antalet kontroller snabbt avtog. Om jag antar att hälften av 2651 märkta boungarna var honor, motsvarar de 34 kontrollerna endast 2,6\%. När det gäller honor som märkts som $2 \mathrm{~K}+$ var antalet kontroller mycket högre, 68 av 293, dvs. 23,3\% Intressant är att notera att $65 \%$ av dessa gjorts inom samma holkgrupp (inom ca 200 meter) och i flera fall i samma holk. Hos de honor som kläckts året innan finns inte samma tendens, de verkar sprida ut sig i hela holkbeståndet (200-1000 meter från födelseplatsen).

Tabell 4. Antal kullar som drabbats av olika slags förluster och andra missöden under olika skeden av häckningscykeln åren 1986-2005. Antalet störningar är i många fall flera än antalet kullar, då flera utsatts för flera förluster och missöden.

Number of clutches affected by different kinds of losses during different phases of the breeding cycle in 19862005. In several years the number of losses is larger than number of clutches because some clutches were affected by more than one kind of disturbance.

\begin{tabular}{|c|c|c|c|c|c|c|c|}
\hline & \multirow{2}{*}{$\begin{array}{l}\text { Antal } \\
\text { kullar } \\
\text { No. of } \\
\text { clutches }\end{array}$} & \multicolumn{2}{|c|}{$\begin{array}{l}\text { Ruvningsperioden } \\
\text { Incubation period }\end{array}$} & \multicolumn{2}{|c|}{$\begin{array}{l}\text { Matningsperioden } \\
\text { Nestling period }\end{array}$} & \multirow{2}{*}{$\begin{array}{r}\text { Döda } \\
\text { ungar efter } \\
\text { utflygning } \\
\text { Dead } \\
\text { young after } \\
\text { fledging }\end{array}$} & \multirow{2}{*}{$\begin{array}{r}\text { Utan } \\
\text { förlust } \\
\text { Without } \\
\text { loss }\end{array}$} \\
\hline & & $\begin{array}{l}\text { Del av } \\
\text { kullen } \\
\text { Part of } \\
\text { clutch }\end{array}$ & $\begin{array}{r}\text { Övergiven } \\
\text { plundrad } \\
\text { Deserted } \\
\text { depredated }\end{array}$ & $\begin{array}{r}\text { Hela } \\
\text { kullen } \\
\text { Whole } \\
\text { brood }\end{array}$ & $\begin{array}{c}\text { Del av } \\
\text { kullen } \\
\text { Part of } \\
\text { brood }\end{array}$ & & \\
\hline 1986 & 21 & 6 & 2 & 0 & 0 & 0 & 13 \\
\hline 1987 & 18 & 9 & 1 & 3 & 1 & 2 & 5 \\
\hline 1988 & 27 & 13 & 2 & 0 & 2 & 0 & 11 \\
\hline 1989 & 35 & 15 & 12 & 4 & 0 & 0 & 5 \\
\hline 1990 & 45 & 13 & 7 & 9 & 6 & 1 & 12 \\
\hline 1991 & 38 & 8 & 9 & 8 & 3 & 5 & 8 \\
\hline 1992 & 30 & 13 & 7 & 3 & 3 & 1 & 5 \\
\hline 1993 & 33 & 14 & 6 & 6 & 4 & 0 & 8 \\
\hline 1994 & 24 & 19 & 4 & 6 & 0 & 1 & 0 \\
\hline 1995 & 10 & 3 & 4 & 3 & 0 & 0 & 1 \\
\hline 1996 & 18 & 1 & 8 & 2 & 0 & 0 & 6 \\
\hline 1997 & 23 & 9 & 5 & 4 & 5 & 2 & 2 \\
\hline 1998 & 24 & 14 & 2 & 3 & 0 & 1 & 6 \\
\hline 1999 & 28 & 12 & 7 & 6 & 0 & 1 & 3 \\
\hline 2000 & 22 & 12 & 3 & 1 & 1 & 4 & 4 \\
\hline 2001 & 18 & 7 & 7 & 4 & 0 & 0 & 1 \\
\hline 2002 & 20 & 12 & 2 & 0 & 0 & 0 & 3 \\
\hline 2003 & 35 & 17 & 10 & 7 & 2 & 2 & 2 \\
\hline 2004 & 23 & 10 & 6 & 5 & 0 & 0 & 4 \\
\hline 2005 & 23 & 12 & 7 & 8 & 0 & 0 & 1 \\
\hline $\begin{array}{l}\text { Summa } \\
\%\end{array}$ & 515 & 219 & 111 & 82 & 27 & 20 & $\begin{array}{r}100 \\
19,4\end{array}$ \\
\hline
\end{tabular}


Tabell 5. Kontroller av ringmärkta honor av talgoxe under perioden 1986-2005.

Number of females that were controlled in the period 1986-2005.

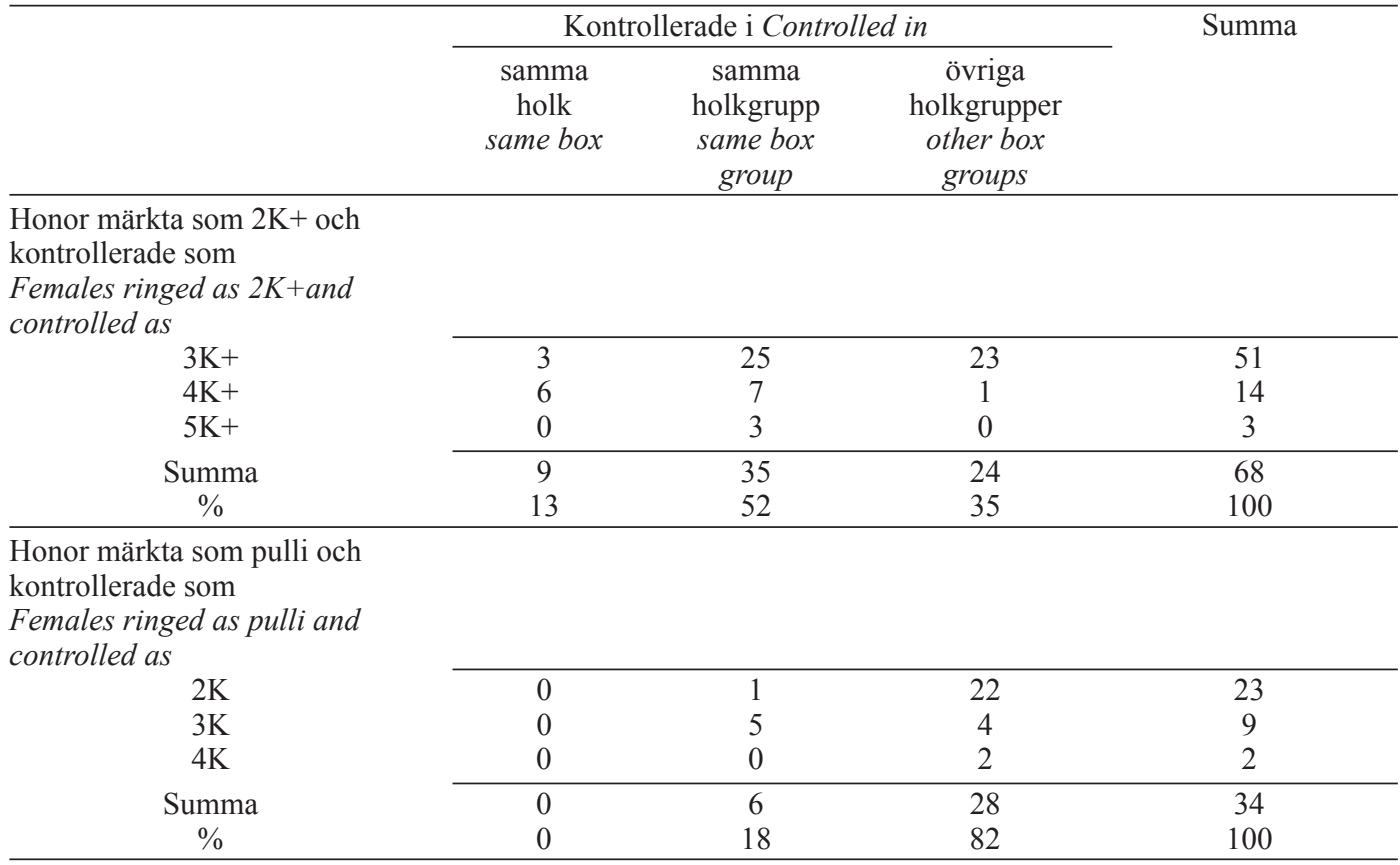

\section{Referenser}

Borgström, E. 2007. Häckningsbiologiska rön från en långtidsstudie över en skandinavisk population av talgoxe $\mathrm{Pa}$ rus major. Ornis Svecica 17: 65-74.

Johansson, H. 1972. Clutch size and breeding success in some hole-nesting passerines in Central Sweden. Ornis Fennica 49: 1-6.

Källander, H. 1983. Aspects of the breeding biology, migratory movements, winter survival and population fluctuations in the Greta Tit Parus major and the Blue Tit Parus caeruleus. Doktorsavhandling, Lund.

Nilsson, J.-E. 2008. Reultat av 20 års holkstudier - främst rörande svartvit flugsnappare Ficedula hypoleuca. Ornis Svecica 18: 52-64.

Schölin, K.G. 2009. En långtidsstudie av talgoxens Parus major häckningsbiologi i ett mellansvenskt blandskogsområde. Ornis Svecica 19: 222-232.

\section{Summary}

This study is a part and continuation of a long-term study of birds breeding in nest-boxes that I started in 1986. The study area and the methods that I have used were described in a previous paper where the numbers and breeding biology of the Pied Flycatcher Ficedula hypoleuca in 1986-2005 were de- scribed (Nilsson 2008). In this study on the Great Tit Parus major I am using another five years in the analyses so that it covers the period 1986-2010.

The study area is at Linderås $\left(57^{\circ} 59^{\prime} \mathrm{N} ; 14^{\circ}\right.$ 48' E), near the town of Tranås in the county of Jönköping. The number of nest-boxes suitable for tits and flycatchers was 94 in 1986-2005. The number was then reduced in steps to 55 in 2010. This means that the data from the last five years are not fully comparable with those from the first twenty years. However, it is unlikely that this had much effect on date of breeding, clutch size or breeding success. But the proportion of different species may partly depend on the number of nest-boxes. I compare the results with those from two other sites, located 140-240 km to the north (Örebro and Råda), sites that have many years in common with my study.

The number of Great Tits in the 94 boxes in 19862005 varied between 12 and 35 (Figure 1) without any significant long-term change. The relationship between minimum and maximum was almost identical with those found at Råda and Örebro (23-72 and 13-41). This means that the relation was $1: 3$ in all three studies. No correlation of numbers could 
be found between the three studies for the common periods. Winter temperature seemed to have little effect as there was no correlation between number of breeding Great Tits and average winter temperature (December-February). There was no significant change of percent occupancy in 1986-2005, but the percentage increased in 2006-2010 so that the positive trend became significant for the whole 25 year period (Figure 2). This was not an effect caused by the adjustment of numbers in relation to the number of nest-boxes as the average absolute number of breeding Great Tits remained about the same (mean 22.2 in the former and 22.6 in the latter period) in spite of fewer nest-boxes.

The mean date of onset of laying varied between years (from 22 April to 9 May) but without any significant trend and with a mean for all 25 years of 2 May (Figure 3). The studies at Råda and Örebro showed the same absence of significant trends. However, there was strong correlation between laying dates when the three sites were compared which was in accordance with the close similarity of spring temperatures. Start of egg laying was closely correlated with April temperature (Figure 4). In spite of this the Great Tits did start to breed significantly earlier. However, this discrepancy may be spurious as the most recent years affect the trends particularly much.
Clutch size declined with on average 0.04 eggs per year during the study period (Figure 5). Similar trends were recorded at Råda and Örebro, and annual clutch size was well correlated between the three sites. Clutch size increased from north to south as demonstrated by the comparison between five sites in Table 1. The earliest clutches were larger than those that were lade later in the season and this was also the case in the Råda study (Table 2).

Fledging success is shown in Table 3. Average number of fledglings was 4.65 which is significantly lower than at Råda (6.81) and Örebro (5.76). I cannot explain this difference but note that also the Pied Flycatcher has a similar low breeding success in my area. Table 4 shows when during the breeding cycle that the losses occur. Only $20 \%$ of the breeding attempts were completely successful, that is that all eggs hatched and all young fledged. The most common kind of loss was that one or two eggs did not hatch. Losses of nestlings were mainly caused by predation or bad weather.

Ring recoveries showed that only $2.6 \%$ of the female nestlings returned to breed in my nest-boxes. Females that were ringed as adults returned to breed at a rate of $23.3 \%$. 